\title{
Advanced Nanomaterials for Energy and Environmental Applications
}

\author{
Chhagan Lal ${ }^{1,2 *}$ and I.P. Jain ${ }^{2}$ \\ ${ }^{1}$ Department of Physics, University of Rajasthan Jaipur, J.L.N. Marg, Jaipur, Rajasthan - 302004, India \\ ${ }^{2}$ Centre for Non-Conventional Energy Resources, University of Rajasthan Jaipur, J.L.N. Marg, Jaipur, Rajasthan - 302004, India
}

${ }^{\star}$ Corresponding author: Dr. Chhagan Lal, Department of Physics and Centre for Non-Conventional Energy Resources, University of Rajasthan Jaipur, J.L.N. Marg, Jaipur, Rajasthan, India; Email: clsaini52@uniraj.ac.in; clsaini52@gmail.com

Received: February 5, 2020; Accepted: April 23, 2020; Published: April 26, 2020

The research areas in the science and engineering have been looking to develop new advance materials for energy technologies, which have the capability of improving life in the world. Globally carbon dioxide emission from fossil fuel combustion increases faster than expected, because of inefficiency in fuel and the weakening of natural carbon sinks. The major source of carbon emissions is the burning fossil fuels and other natural sources. It was observed that nanotechnology able to decrease the need for fossil fuels, thus having a positive impact on global warming. Nanotechnology and its products (or nanomaterials) mostly involve in the applications of renewable energies (such as, solar and hydrogen fuel cells and energy storage device), which result in nearly zero $\mathrm{Co}_{2}$ emissions. Increasing the use and efficiency of renewable/ecofriendly energy resources will overcome the use of burning fossil fuel, and at the same time decreasing the consumption of current fuels is one way to slow down and ultimately stop global warming. The advance development in nanomaterials is still in progress, which can economically absorb the carbon dioxide from the air, capture toxic pollutants from water and degrade solid waste into useful products. Nanomaterials are efficient catalysts and mostly recyclable.

\section{(1) Advance Nanomaterials for Energy Storage applications:}

Hydrogen today is enjoying unprecedented state in the world in emerging fields of renewable energy by substitution of fossil fuels (i.e. petroleum, natural gas and coal), which meet most of the world's energy demand today, are being depleted fast. Combustion products of fossil fuel are creating global problems (global warming, climate change, ozone layer depletion, acid rain, oxygen depletion and pollution), which posing great danger for our environment and eventually for life on our planet. Scientists all over the world agree to replace the existing fossil fuel system with the Hydrogen Energy System. Hydrogen is the fuel of $21^{\text {st }}$ century because of it being light, most abundant, storable, energy-dense, and produces no direct emissions of pollutants or greenhouse gases. Hydrogen energy has potential to solve energy problems of the planet earth giving it a sustainable and safe future, resulting into a clean planet. $\mathrm{H} 2$ storage and release is a key challenge which is solved by metal hydrides which can absorb hydrogen in atomic form and release it easily by raising their temperature or pressure. Lots of important advances have been resulted during last one decade for developing nanostructure materials with high volumetric and gravimetric hydrogen capabilities. There is an urgent need to developed low cost, safe and inexpensive nanostructured hydride materials having high hydrogen content and fast desorbing properties at low temperature and pressure. In the present energy scenario, most of hydrogen storage materials have storage capacities not more than $5 \mathrm{wt} \%$ which is not satisfactory for practical application as per DOE USA Goal. Many research groups are currently working on hydrogen storage material to get best de/ absorption kinetics with ultimate $\mathrm{H}_{2}$ contents. e.g. $\mathrm{Mg}$ hydride is a promising hydrogen storage material with reversible hydrogen capacity up to $7.6 \mathrm{wt} \%$ for on board applications with fast kinetics, good cycle life and decreased hydrogen desorption temperature. Good hydrogen storage properties are possible by introducing enough catalyst and by ball milling which introduces defects with improved surface properties. Hence lot of research work is needed for improving metal hydrides properties such as hydrogenation, fast charging / discharging rate, fast kinetics, thermal and cyclic behaviour. All over the world serious type of research and development work is going on Hydrogen Energy. Internal combustion engines are being modified for hydrogen fuel. Efficient fuel cells are being developed to convert hydrogen efficiently to electricity. Research and development work on metal hydride refrigeration and air conditioning systems is in advance stages and will be available for commercial applications shortly. Hydrogen fuel subsonic and supersonic transport planes are already in their test runs, In fact hydrogen shows the solution and is capable of the progressive and non-traumatic transition of today's world energy scenario to feasible, safe, reliable and completely sustainable energy future. Scientists are advocating use of hydrogen for all types of energy applications which was earlier possible only by fossil fuel and they have hoped for the international response to the global climate change. Hence there are enough environmental and public health benefits of direct use of hydrogen energy and justifying for moving ahead, based on what we already know about fossil fuels and their consequences.

\section{(2) Advance Nanomaterials for Solar Cell Applications:}

Solar cell materials are the current prospects for clean energy research to offering strong power outputs from low-cost raw materials 
that are relatively simple to process into working devices. Although the potential of the material (Perovskite based solar cells) is just starting to be understood, it has caught the attention of the world's leading solar researchers are trying to commercialize it. e.g. organicinorganic lead halide perovskite solar cells are contenders in the drive to provide a cheap and clean source of energy with electrical power conversion efficiencies of over $29 \%$. The high efficient photovoltaic materials are recognized for optically high absorption characteristics and balanced charge transport properties with long diffusion lengths. Nevertheless, there are lots of puzzles to unravel to understand the fundamental basis of such advance materials. Perovskite solar cells
(PSC) are economically viable from a viewpoint of efficiency, however, commercialization is still challenging because of the toxicity of lead, long term stability, and cost-effectiveness. Future research directions will benefit from finding lead-free light-absorbing materials. However, the reported efficiencies are thus far too low to commercialize PSC's. The cost-effectiveness of the raw materials and the fabrication processes is a significant issue. High throughput fabrication strategies with reproducible materials and processes should be developed. Moreover, mechanical functionalities such as flexibility, stretchable and long term stability properties will lead to making PSC's more economically viable. 